\title{
Genetic variations in the pre-feeding and pre-oviposition periods among four pure lines in the brown planthopper, Nilaparvata lugens (Hemiptera: Auchenorrhyncha:Delphacidae)
}

\author{
Makoto Inada · Sunao Morooka $\cdot$ Kyo Itoyama • \\ Sumio Tojo
}

Received: 11 April 2011/Accepted: 1 September 2011/Published online: 5 October 2011

(C) The Author(s) 2011. This article is published with open access at Springerlink.com

\begin{abstract}
In the brown planthopper, Nilaparvata lugens Stål, traits related to ovarian development were compared among four pure lines predominantly expressing the designated characteristics: blackish short-winged (BS), yellowish brown short-winged (YS), blackish long-winged (BL), and yellowish brown long-winged (YL). The preoviposition period was longer in the following order: $\mathrm{BS}<\mathrm{YS}<\mathrm{BL}=\mathrm{YL}$ line. The pre-feeding period, namely, the time of non-feeding after adult emergence, which was estimated from dry weight loss during starvation, was also longer in the same order: $\mathrm{BS}<\mathrm{YS}<$ $\mathrm{BL}=\mathrm{YL}$. Vitellogenin, the precursor of yolk protein, first appeared in the hemolymph about $1 \frac{1}{2}$ days later after the initiation of feeding in respective lines. One-day's starvation did not have any effect on the timing of vitellogenin's appearance in the long-winged lines (BL, YL), but delayed it by 1 day in the short-winged lines (BS, YS). Further, we
\end{abstract}

M. Inada $\cdot$ S. Morooka $\cdot$ K. Itoyama $\cdot$ S. Tojo $(\varangle)$

Department of Applied Biological Sciences,

Faculty of Agriculture, Saga University, Honjyo,

Saga 840-8502, Japan

e-mail: tojos@cc.saga-u.ac.jp

Present Address:

M. Inada

Biological Research Laboratories, Nissan Chemical Industries,

Ltd, Shiraoka, Saitama 349-0294, Japan

Present Address:

S. Morooka

The Department of Health and Welfare, Saga Women's Junior

College, Honjyo, Saga 840-0842, Japan

Present Address:

K. Itoyama

School of Agriculture, Meiji University, Higashimita,

Tama-ku, Kawasaki 214-8571, Japan showed that the synthesis of vitellogenin mRNA was induced in the adults even before feeding by being topically applied with juvenile hormone III (JH III). These results suggest that feeding first triggers the increase of JH III titer, which activates vitellogenin synthesis, and enhances ovarian development. Thus, genetic differences in the prefeeding periods cause the differences in the timings of physiological events relating to ovarian development among the four lines.

Keywords Pre-oviposition period - Pre-feeding period . Vitellogenin · Juvenile hormone · Genetic variation

\section{Introduction}

Wing polymorphism is one of the strategies for adapting to environments in various orders of insects, mostly in Hemiptera and Orthoptera: long-winged (macropterous) and short-winged (brachypterous) or wingless morphs differ in several life-history traits (Harrison 1980; Roff 1986, 1990; Fujisaki 2004).

An auchenorrhynchan, the brown planthopper, Nilaparvata lugens Stål, is well known for its wing dimorphism, exhibiting macropterous and brachypterous wing forms, the expression of which is largely influenced by nymphal density (Kisimoto 1956, 1965; Watanabe 1967; Iwanaga and Tojo 1986). The macropters have longer nymphal and pre-oviposition periods, lower fecundity, and higher tolerances to starvation and dryness than the brachypters (Kisimoto 1965). These characteristics are considered to render the macropters adaptable to a migratory mode of life and the brachypters to a sedentary mode of life.

The wing-form responses to density in $N$. lugens are fundamentally under genetic control (Iwanaga et al. 1985, 
1987; Morooka et al. 1988). In our laboratory, four pure lines have been generated by selection over 30 generations for adults emerging at high rearing density: blackish shortwinged (BS), yellowish brown short-winged (YS), blackish long-winged (BL), and yellowish brown long-winged (YL) (Morooka and Tojo 1992). By extensive crossing experiments using these pure lines, Morooka (1992) proposed two major gene models for respective wing-form and bodycolor determination, one allele on an autosome and another allele on the X sex-chromosome. The four pure lines differ not only in body-color and wing-form expression, but also in developmental time, which is in the following order: $\mathrm{BS}<\mathrm{YS}=\mathrm{BL}<\mathrm{YL}$ lines (Morooka et al. 2011). These findings suggest the involvement of genes regulating body color and wing form in other life-history traits.

The present study aimed to find genetic variation in relation to ovarian development, especially the pre-oviposition and pre-feeding periods among the four pure lines. The duration of pre-oviposition period is one of the key factors for reproductive success in wing-polymorphic species. Flightless adults that have short wings or underdeveloped flight muscles begin ovarian development earlier than flight-capable adults (Harrison 1980; Roff 1986; Zera and Denno 1997). In N. lugens, a shorter prefeeding period after adult emergence in the brachypters compared with the macropters was demonstrated by comparing the periods between the black-colored shortwinged BS line and long-winged BL line of $N$. lugens (Itoyama et al. 1999), these two lines being used in the present study.

In insects that develop ovaries during adulthood, ovarian development and vitellogenin synthesis are stimulated by juvenile hormone (Bownes 1986; Raikhel and Dhadialla 1992; Wyatt and Davey 1996). In N. lugens, juvenile hormone III (JH III) is identified as the sole JH (Bertuso and Tojo 2002). The titer in the hemolymph differently changes between the brachypters (the BS pure line) and the macropters (the BL line) during early adulthood (Bertuso and Tojo 2002). Topical application of JH III to the macropters enhances ovarian development as in the brachypters (Iwanaga and Tojo 1986). These findings support the involvement of $\mathrm{JH}$ in the regulation of ovarian development. Recently, the vitellogenin gene was cloned in $N$. lugens, and its expression was found to be enhanced by exogenous JH III and to occur earlier in the brachypters than macropters (Tufail et al. 2010). Since vitellogenin is the yolk protein precursor, it is used as a predictor of fecundity in many species, including the soldier bug, Podisus maculiventris Say (Shapiro et al. 2000).

Based on these findings, we tried to determine how the physiological events proceed before egg laying among these four pure lines, noting the timing of vitellogenin's appearance in the hemolymph and its gene expression.

\section{Materials and methods}

Insects

The four pure lines of $N$. lugens were generated by selection over 30 generations for specific body-color and wing-form expressing adults that emerged from nymphs reared at high density and maintained for over 100 generations in our laboratory. Nymphs of the four lines were reared in cylindrical acryl-resin cages (i.d. $5.4 \mathrm{~cm} \times$ height $22 \mathrm{~cm}$ ) containing about 130 rice seedlings (variety Reiho) at high density (200 nymphs per cage) under a $16 \mathrm{~L}: 8 \mathrm{D}$ photoperiodic regime at $25 \pm 1^{\circ} \mathrm{C}$, as previously described (Morooka and Tojo 1992).

Females and males were separated within $6 \mathrm{~h}$ after adult emergence. A single female was put in a test tube cage (i.d. $2.0 \mathrm{~cm} \times$ height $18 \mathrm{~cm}$ ) containing five rice seedlings with two males (2-day old). For a starvation experiment, respective females were reared in a test tube containing a piece of wet cotton to prevent the dehydration for 1 or 2 days, and then transferred into another test tube containing five seedlings with two males. The seedlings were renewed every day and checked for eggs laid by the females. These adults were maintained in similar conditions with a temperature and photoperiodic regime as for nymphal rearing and used for subsequent analyses.

\section{Estimation of the pre-feeding period}

The pre-feeding period after adult emergence was estimated by comparing changes in dry weight between fed and starved females, both unmated (Itoyama et al. 1999). Six to eight individuals were lyophilized for $4 \mathrm{~h}$ and weighed as one sample. More than six samples were weighed to obtain one value.

\section{Collection of hemolymph}

To collect hemolymph sample, three adults were carefully torn at an intersegmental membrane with fine tweezers and dipped in $30 \mu \mathrm{l}$ of KPB $(20 \mathrm{mM}$ potassium phosphate, $150 \mathrm{mM} \mathrm{NaCl}, 2 \mathrm{mM}$ EDTA, $0.02 \% \mathrm{NaN}_{3}, \mathrm{pH}$ 6.8) containing protease inhibitors $(0.5 \mathrm{mM}$ phenylmethyl sulfonyl fluoride, $1 \mu \mathrm{g} / \mathrm{ml}$ pepstatin $\mathrm{A}, 1 \mu \mathrm{g} / \mathrm{ml}$ leupeptin, and $2 \mathrm{mM}$ dithiothreitol) in a $1.5 \mathrm{ml}$ tube. Gentle tapping of the tube eluted out the hemolymph into the solution. After centrifugation $\left(2,000 \mathrm{~g}, 15 \mathrm{~min}, 4^{\circ} \mathrm{C}\right)$, the supernatant was collected and stored at $-20^{\circ} \mathrm{C}$.

Sodium dodecyl sulfate polyacrylamide gel electrophoresis

The hemolymph sample was boiled for 3 min after being added with two volumes of sodium dodecyl sulfate 
polyacrylamide gel electrophoresis (SDS-PAGE) sample buffer [0.125 M Tris-HCl, pH 6.8, 20\% glycerol, $2.5 \%$ SDS, $10 \%$ 2-mercaptoethanol, and $0.02 \%$ (W/V) bromophenol blue]. SDS-PAGE was performed on a $7.5 \%$ polyacrylamide gel as described by Laemmli (1970). After the electrophoresis, proteins were stained with Coomassie Brilliant Blue R-250 (CBB R-250) (Weber et al. 1972).

Preparation of antibody

One thousand eggs were homogenized in KPB containing protease inhibitors and centrifuged $(18,000 \mathrm{~g}, 10 \mathrm{~min}$, $\left.4^{\circ} \mathrm{C}\right)$. The supernatant was mixed with two volumes of SDS-PAGE sample buffer, boiled for $3 \mathrm{~min}$, and separated by SDS-PAGE. After staining with CBB R-250 for $30 \mathrm{~min}$, the gel was destained in aqueous $35 \%$ methanol-5\% acetic acid for $1 \mathrm{~h}$, and the band corresponding to vitellin was excised and washed twice with water for $30 \mathrm{~min}$ to remove SDS. The gel slice was frozen at $-20^{\circ} \mathrm{C}$, lyophilized using a centrifugal concentrator (VC-360, TAITEC Co.) under reduced pressure, and ground into powder using a medicine spoon. The powder was suspended in $0.7 \mathrm{ml}$ of water and emulsified with an equal amount of Freund's complete adjuvant. The emulsion was injected into the dorsal parts of a rabbit. Two additional injections were carried out with Freund's incomplete adjuvant at intervals of 10 days. The rabbit was bled 10 days after the last injection, and the antiserum thus obtained was stored at $-20^{\circ} \mathrm{C}$ prior to use.

\section{Western blot analysis}

After SDS-PAGE, proteins in a gel were transferred onto a nitrocellulose membrane (Towbin et al. 1979) using Mini Protein Cell (Bio-Rad). The membrane was then blocked with $5 \%$ skim milk in TBS $(0.1 \mathrm{M}$ Tris-HCl-0.1 M NaCl, $\mathrm{pH} 8.0$ ) for $30 \mathrm{~min}$ at room temperature and incubated in $5 \%$ skim milk in TBS containing rabbit antiserum against vitellin $(1 / 2,000)$ overnight at $4^{\circ} \mathrm{C}$. The anti-vitellin serum was prepared as described below. Goat anti-rabbit IgG conjugated with alkaline phosphatase (E. Y. Labs. Inc.) was used as the secondary antibody. Ten milliliters of TSM (100 mM Tris- $\mathrm{HCl}, 100 \mathrm{mM} \mathrm{NaCl}, 50 \mathrm{mM} \mathrm{MgCl}_{2}, \mathrm{pH}$ 9.5) containing $45 \mu \mathrm{l}$ of NBT (nitroblue tetrazolium, $75 \mathrm{mg} / \mathrm{ml}$ in $70 \%$ dimethylformamide) and $35 \mu \mathrm{l}$ of $\mathrm{X}$-phosphate (5-bromo-4-chloro-3-indolyl phosphate $p$ toluidine salt) was used as a substrate for the detection of alkaline phosphatase.

Preparation of partial vitellogenin cDNA

Messenger RNA was extracted from 25 adult females by using MICRO-FASTTRACK ${ }^{\mathrm{TM}} 2.0$ (Invitrogen). One $\mu \mathrm{g}$ of mRNA was used for construction of an adapter-ligated double-strand cDNA library using a marathon cDNA amplification kit (Clontech) according to the manufacture's instruction. The adapter-ligated double-strand cDNA library was subjected to polymerase chain reaction (PCR) using a pair of primers. GL/ICG primer ( $5^{\prime}$ GGGCTCTGCGC $3^{\prime}$ ) was designed from the GL/ICG motif conserved for insect vitellogenin (Lee et al. 2000). PCR was carried out using a program temp control system (PROGENE; Techne). The employed standard cycling conditions were $95^{\circ} \mathrm{C}$ for $1 \mathrm{~min}$ for denaturation, followed by 28 cycles of $95^{\circ} \mathrm{C}$ for $30 \mathrm{~s}$, $55^{\circ} \mathrm{C}$ for $30 \mathrm{~s}$, and $68^{\circ} \mathrm{C}$ for $2 \mathrm{~min}$.

\section{Northern blot analysis}

Northern hybridization was performed by using DIG Northern Starters Kit (Roche). To make a DIG-RNA labeling probe, $1 \mu \mathrm{g}$ of linearized plasmid DNA containing vitellogenic cDNA ( $N$. lugens $\mathrm{Vg}$-2) was used. One $\mu$ l of total RNA was denatured at $65^{\circ} \mathrm{C}$ for $5 \mathrm{~min}$, separated on a formaldehyde agarose gel (1\%) in MOPS [3-( $N$-molopholino) propane sulfonic acid] buffer, and transferred onto nylon membrane (Hybond $\mathrm{N}+$, Amersham) by capillary action. Hybridization was carried out by incubating the membrane with the DIG Easy Hyb (supplied in the DIG Northern Starters Kit, Roche) containing DIG-labeled RNA probe overnight at $68^{\circ} \mathrm{C}$. After hybridization, the membrane was washed twice in $2 \times \mathrm{SSC}$ (3.33 M NaCl, 3.33 M trisodium citrate dihydrate) $/ 0.1 \% \mathrm{SDS}$ for $5 \mathrm{~min}$ at room temperature and twice in $0.2 \times \mathrm{SSC} / 0.1 \% \mathrm{SDS}$ for $15 \mathrm{~min}$ at $68^{\circ} \mathrm{C}$. Hybridized probe was immunodetected with anti-digoxigenin-AP; Fab fragments are then visualized with the chemiluminescence substrate CDP-Star, ready-to-use (all supplied in the DIG Northern Starters Kit, Roche). The signal was detected by exposure to an X-ray film.

\section{JH III treatment}

JH III was dissolved in acetone to yield $100 \mu \mathrm{g} / \mathrm{ml}$ as stock solution. The stock solution was serially diluted with acetone just before use. One hundred pg of JH III dissolved in $0.1 \mu \mathrm{l}$ of acetone was topically applied onto the abdomen of the YB line females by using a $10 \mu \mathrm{l}$ syringe (Terumo) and a micro applicator (Burkard), after anesthetization with $\mathrm{CO}_{2}$ for $30 \mathrm{~s}$.

\section{Results}

Comparison of the pre-oviposition period among the four pure lines

The pre-oviposition period was estimated as the time after adult emergence when half of the females were found to 
lay eggs. As shown in Fig. 1, the pre-oviposition period differed among the four lines, longer with the order $\mathrm{BS}<\mathrm{YS}<\mathrm{BL}=\mathrm{YL}$ (Fig. 1).

The pre-feeding period deduced from changes in dry weight

The pre-feeding period, namely, the time when the adult starts sucking after emergence, was deduced from the changes in dry weight between the fed and non-fed adults. As shown in Fig. 2, the BS line showed significant increases in

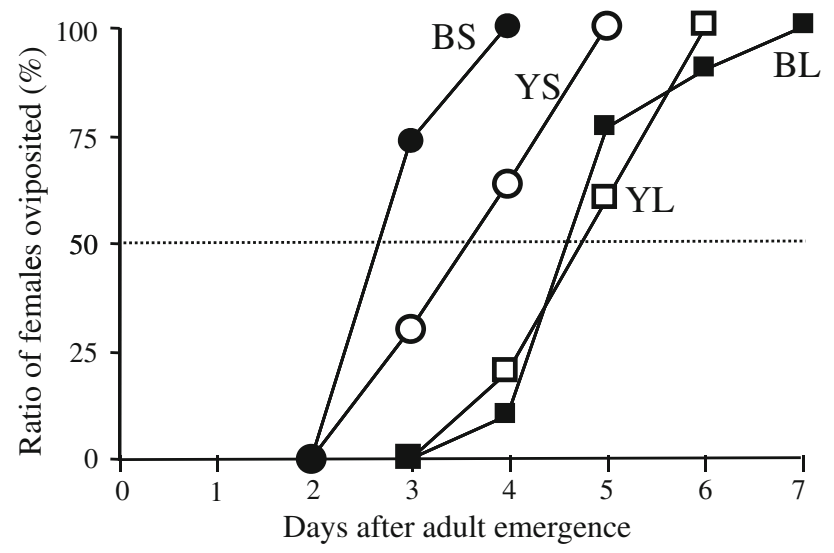

Fig. 1 Comparison of pre-oviposition periods among blackish shortwinged (BS), yellowish brown short-winged (YS), blackish longwinged (BL), and yellowish brown long-winged (YL) lines of $N$. lugens. Thirty individuals were used for each line

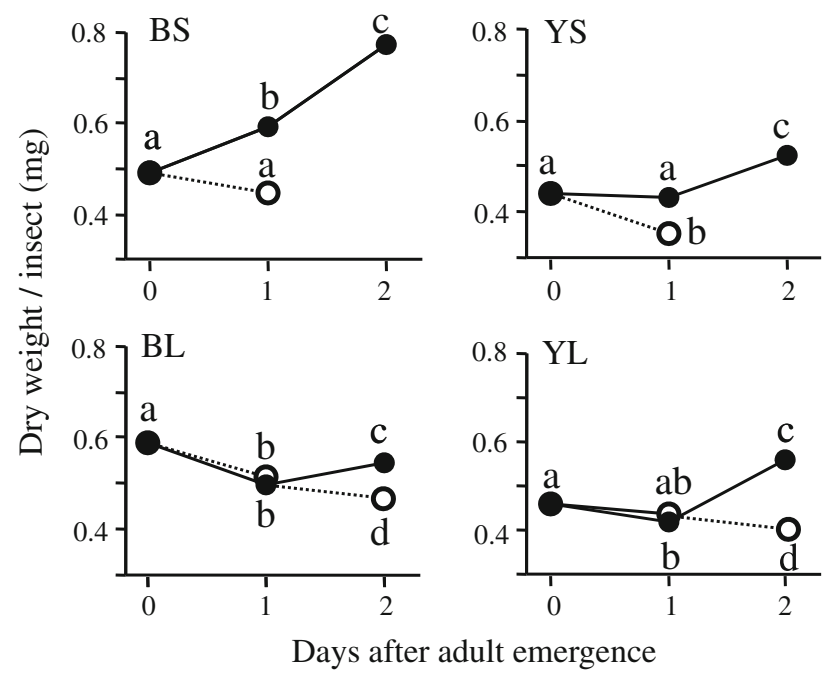

Fig. 2 Comparison of dry weight change between female adults reared under fed (reared with rice seedlings, filled circles) and starved (without rice seedlings, open circles) conditions in the four pure lines of $N$. lugens. Females within $6 \mathrm{~h}$ after emergence were separately reared with males in both conditions. Different letters indicate significant differences by Fisher's PLSD $(p<0.05)$. Standard errors are within the symbols $(n=6-8)$. See Fig. 1 for the names of the pure lines dry weight for 2 days in the fed condition. When starved for 1 day, it had a significantly lower weight than the fed control $(p<0.05)$, although it did not significantly differ from the 0 -day level (Fisher's PLSD, $p=0.142$ ). In the YS line, there was no difference in dry weights between 0-day and 1-day adults under the fed condition $(p=0.724)$, but 1 day's starvation significantly decreased the weight below the 0 -day level $(p<0.05)$. These results indicate that the BS line starts feeding soon after adult emergence, namely, the pre-feeding period is 0 day, while the period is longer in the YS line, but less than 1 day.

In the long-winged lines (BL and YL), weight was not significantly lost in those starved for 1 day after adult emergence (BL, $p=0.692$; YL, $p=0.281$ ), whereas starvation for 2 days caused a significant loss of dry weight, compared to 1 day's starvation $(p<0.01)$, and feeding for this period brought a significant increase in weight $(p<0.01)$. These results indicate that the non-feeding period after adult emergence in the BL and YL lines was longer than 1 day, but less than 2 days. Thus, the pre-feeding period was longer, as in the following order: $\mathrm{BS}<\mathrm{YS}<\mathrm{BL}=\mathrm{YL}$, as in the order of the pre-oviposition period.

\section{Identification of vitellogenin}

As such differences in the pre-oviposition and pre-feeding periods were expected to be reflected in the timing of vitellogenin synthesis, further analysis was conducted on this protein. As shown in Fig. 3a, two female-specific polypeptides of 180 and $46 \mathrm{kDa}$ were found on SDS-PAGE of the hemolymph of female adults. These bands were also seen in egg extract as major protein bands. In the Western

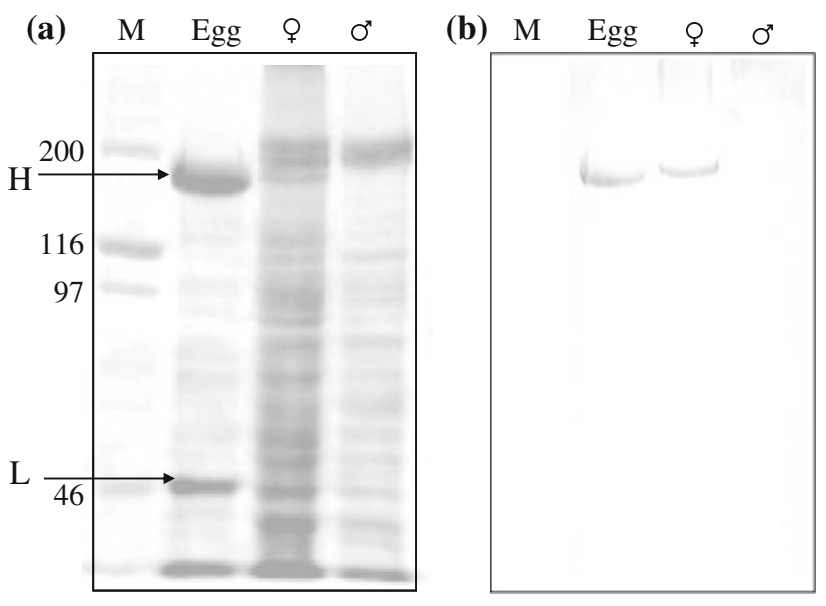

Fig. 3 Detection of vitellogenin in N. lugens. Proteins were separated by SDS-PAGE on $7.5 \%$ acrylamide, and stained with Coomassie Brilliant Blue R250 (a) or immunostained with the antiserum prepared against $180 \mathrm{kDa}$ egg protein, namely, the heavy chain of vitellogenin (b). M, marker proteins; Egg, egg extract; ㅇ, hemolymph of female adult; $\hat{\sigma}$, hemolymph of male adult 

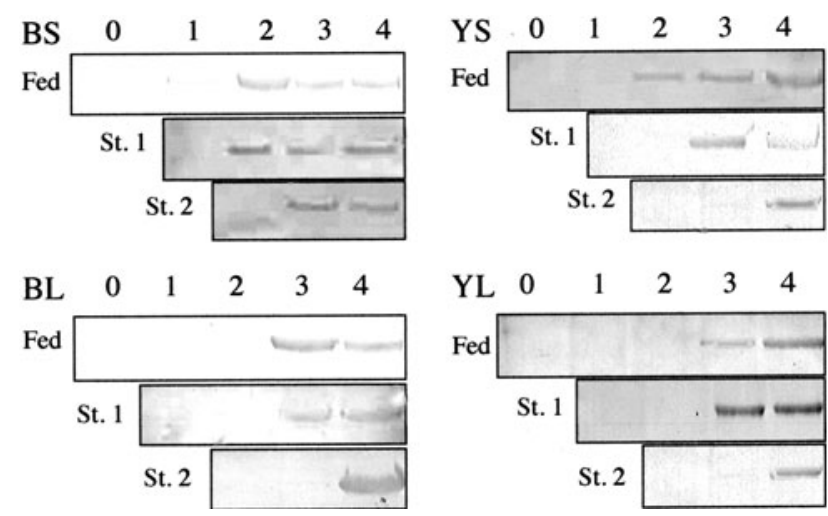

Fig. 4 Comparison of the timing of vitellogenin's appearance in the hemolymph among four pure lines under fed or starved conditions. St. 1, St. 2: starved for 1 or 2 days after adult emergence, respectively. The numbers are days after emergence. Vitellogenin was detected by Western blot analysis using the antiserum against its large subunit. Hemolymph sample from three individuals was loaded in a lane

blot analysis, antiserum against the $180 \mathrm{kDa}$ protein in the egg extract cross-reacted solely with the $180 \mathrm{kDa}$ peptide from the female hemolymph (Fig. 3b). These results indicate that the $180 \mathrm{kDa}$ peptide is the heavy chain of vitellogenin, and so the antiserum against the peptide can be used to specifically detect vitellogenin's heavy chain.

Timing of vitellogenin's appearance in the hemolymph in fed and non-fed adults

As shown in Fig. 4, in fed adults, vitellogenin first appeared in the hemolymph of 1-day old BS, 2-day old YS, and 3-day old BL and YL adults. As the vitellogenin band in 1-day old BS was too weak, the time of its first appearance seems to be between 1 and 2 days after adult emergence. Thus, the timing of its appearance was ca. $1 \frac{1}{2}$ days earlier than that of oviposition with the respective lines.

Figure 4 also shows the influence of starvation on the timing of vitellogenin's appearance in the hemolymph. One day's starvation in the short-winged lines (BS and YS) delayed the timing by 1 day compared with that of fed controls. The vitellogenin's appearances in the long-winged lines (BL and YL) were not influenced by 1-day's starvation. Two day's starvation delayed the appearance by 2 days in both short-winged lines, but by 1 day in the two long-winged lines compared with that of the fed controls, supporting further the presence of a pre-feeding period, longer than 1 day but shorter than 2 days, in the long-winged lines.

Timing of vitellogenin mRNA synthesis in fed and non-fed adults

Further, the timing of vitellogenin mRNA synthesis and the effects of starvation on it were compared in YS and
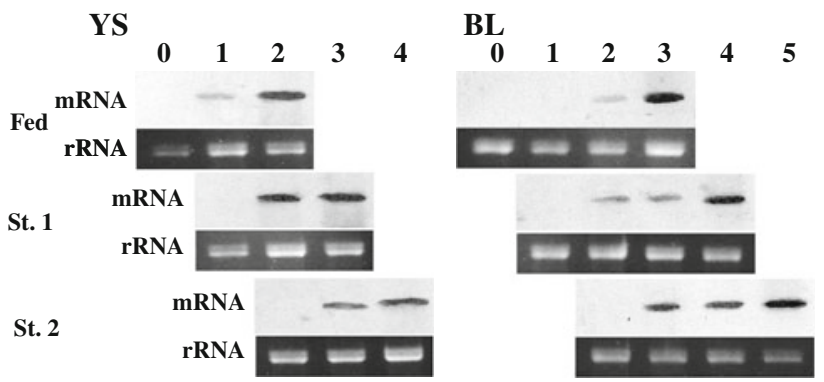

Fig. 5 Detection of vitellogenin mRNA in the YS and BL lines of $N$. lugens under fed (Fed) or 1- or 2-day starved (St. 1, St. 2) conditions starting shortly after emergence. Numbers are days after adult emergence. Vitellogenin mRNA was detected by Northern blot analysis. Ethidium bromide staining of rRNAs shows roughly same amount of total RNAs being loaded in each lane

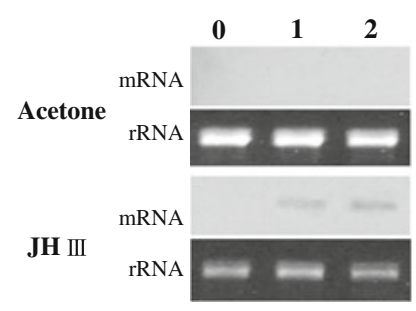

Fig. 6 Effect of JH III on vitellogenin mRNA synthesis in the BL line of $N$. lugens. Newly emerged adults were topically applied to their abdomen with either $0.1 \mu \mathrm{l}$ of acetone (Acetone) or $100 \mathrm{pg}$ of JH III dissolved in $0.1 \mu \mathrm{l}$ of acetone (JH III), and kept without food for 2 days. Ethidium bromide staining of rRNAs shows roughly same amount of total RNAs being loaded in each lane

BL pure lines (Fig. 5). In the YS line, vitellogenin mRNA was first detected 1 day after adult emergence, and the timing of the synthesis was delayed as the starvation period was extended up to 2 days. In the BL line, vitellogenin mRNA was first detected 2 days after emergence. One day's starvation did not change the timing of the synthesis of vitellogenin mRNA; however, 2-day starvation delayed it by 1 day compared to fed control. In all conditions, the vitellogenin mRNA level increased day by day.

\section{Effects of JH III application on transcription} of vitellogenin

To clarify the effect of juvenile hormone on vitellogenin synthesis, $100 \mathrm{pg}$ of JH III was topically applied to the females of the YS line shortly after emergence, and mRNAs were prepared from the females kept in starved condition. While vitellogenin mRNA was not detected in acetone-treated control, it clearly existed in the $\mathrm{JH}$ III-treated females, 1 and 2 days after adult emergence (Fig. 6). 


\section{Discussion}

Relationship between the pre-oviposition and pre-feeding periods

In wing-polymorphic insects, flightless morphs have a shorter pre-oviposition period, and so are able to settle earlier than in flight-capable morphs, which are able to disperse and migrate (Harrison 1980; Roff 1986; Zera and Denno 1997). In addition, in N. lugens, brachypters deposit eggs earlier than macropters (Kisimoto 1965). In the present study, we demonstrated that the pre-oviposition period differs among four lines of $N$. lugens, which predominantly exhibit a specific wing form and body color over a broad range of rearing densities (Morooka and Tojo 1992). The pre-oviposition period, the time when half of the females deposited eggs after adult emergence, was in the following order: $\mathrm{BS}<\mathrm{YS}<\mathrm{BL}=\mathrm{YL}$ pure lines, the differences among them being ca. 2 days (Fig. 1). The finding that the pre-oviposition periods in the two brachypterous lines of BS and YS were shorter by 1 or 2 days than those in the long-winged lines BL and YL (Fig. 1) does not conflict with the results of Kisimoto (1965), obtained using a non-selected population.

We further found differences among four lines in the pre-feeding period, which was detected by comparisons of dry weights between fed and starved adults: 0 day in BS, less than 1 day in YS, and less than 2 days in BL and YL lines (Fig. 2). Thus, the differences in the pre-feeding period were ca. 2 days. Namely, the variation in the preoviposition period correlates well with the difference in the pre-feeding period. In addition, the shorter pre-feeding period in brachypters versus macropters as reported by Itoyama et al. (1999), who used BS and BL lines, was reconfirmed by the present study.

\section{$\mathrm{JH}$ and vitellogenin}

The time of vitellogenin's appearance differed among the four lines (Fig. 4), but in all of them, vitellogenin appeared 1 day after the initiation of feeding, followed by oviposition, which occurred a further $1 \frac{1}{2}$ days later. In addition, we demonstrated the stimulation of vitellogenin synthesis by JH III, and earlier synthesis of vitellogenin mRNA in the short-winged BS line by 1 day compared to the longwinged YL line (Figs. 5, 6). Our results confirmed the recent findings that vitellogenin gene expression in $N$. lugens is triggered by JH III, and the transcript first appears 1 day after adult emergence in the brachypters and 2 days in the macropter in none-selected lines (Tufail et al. 2010).

In $N$. lugens, $\mathrm{JH}$ III is identified as the sole $\mathrm{JH}$ (Bertuso and Tojo 2002). The titer in the hemolymph of the brachypters (the BS line) is two-fold higher than in the macropters (the BL line) at 1 day after adult emergence. The titer in the brachypters attains a maximum at 3 days, which corresponds with the timing of the longest oocyte length. In the macropters, the JH titer attains a high level 1 day later than in the brachypters (Bertuso and Tojo 2002). These changes of JH III titer seem to well explain the present results: the BS line starts feeding soon after adult emergence, which triggers JH III synthesis, stimulating vitellogenin synthesis within 1 day, while in the nonfeeding ML line, JH III synthesis is delayed, causing a retardation in vetellogenin gene expression.

\section{Genetically regulated life-history traits}

The four lines used in the present research have been judged to be pure in the composition of genes regulating body-color and wing-form expression by a series of extensive crossing experiments (Morooka 1992). The four pure lines also differed in the nymphal developmental time in females in the following order: $\mathrm{BS}<\mathrm{YS}=\mathrm{BL}<\mathrm{YL}$ lines (Morooka et al. 2011). Further in the present study, we found differences in the pre-oviposition period as $\mathrm{BS}<\mathrm{YS}<\mathrm{BL}=\mathrm{YL}$, reflecting the differences in the pre-feeding period. The line-specific differences in these life history traits suggest the involvement of genes related to the regulation of wing form and body color expression, or other genes with a high linkage to the former gene group, in the regulation of these life-history traits.

\section{Longer pre-feeding period in the macropters}

An important questions arises: Why do the macropters have a 1 day or longer pre-feeding period? Not only having wings but also having highly developed flight muscles is important for long-distance migration in insects (Solbreck et al. 1990). In the pea aphid, Acyrthosiphon pisum Harris, an alatae has a rather long pre-feeding period during which it develops flight muscles and then becomes active in terms of flight (Kobayashi and Ishikawa 1993). In many insects, the timing of oogenesis is regulated by food intake (Wyatt and Davey 1996). For example, in the desert locust, Schistocerca gregaria Forskal (Tobe and Chapman 1979), and the American cockroach, Periplaneta americana Linnaeus (Weaver and Pratt 1981), feeding induces a higher $\mathrm{JH}$ titer, which stimulates vitellogenin synthesis and enhances ovarian development. These results suggest that the non-feeding period is necessary for constructing a body adaptable to migration specifically in the macropters. Our recent findings suggest that flight muscles develop under the absence of JH III during this pre-feeding period in $N$. lugens, to be published elsewhere. 
Open Access This article is distributed under the terms of the Creative Commons Attribution Noncommercial License which permits any noncommercial use, distribution, and reproduction in any medium, provided the original author(s) and source are credited.

\section{References}

Bertuso AG, Tojo S (2002) The nature and titer of juvenile hormone in the brown planthopper, Nilapalbata lugens (Homoptera: Delphacidae) in relation to wing morphogenesis and oocyte. Appl Entomol Zool 13:117-125

Bownes M (1986) Expression of the genes coding for vitellogenin (yolk protein). Annu Rev Entomol 31:507-531

Fujisaki K (2004) Evolution and degeneration of flight in insects. In: Fujisaki K, Tanaka S (eds) Flight and phase polymorphism of insects. Tokai University Press, Hatano, pp 86-103 (in Japanese)

Harrison RG (1980) Dispersal polymorphism in insects. Annu Rev Ecol Syst 11:95-118

Itoyama K, Morooka S, Tojo S (1999) Triacylglycerol storage in the adults of two selected strains of the brown planthopper, Nilaparvata lugens. Appl Entomol Zool 34:171-177

Iwanaga K, Tojo S (1986) Effects of juvenile hormone and rearing density on wing dimorphism and oocyte development in the brown plant hopper, Nilaparvata lugens. J Insect Physiol 32:585-590

Iwanaga K, Tojo S, Nagata $\mathrm{N}$ (1985) Immigration of the brown planthopper, Nilaparvata lugens, exhibiting various responses to density in relation to wing morphism. Entomol Exp Appl 38:101108

Iwanaga K, Nakasuji F, Tojo S (1987) Wing polymorphism in Japanese and foreign strains of the brown planthopper, Nilaparvata lugens. Entomol Exp Appl 43:3-10

Kisimoto R (1956) Effect of crowding during larval period on the determination of the wing-form of an adult planthopper. Nature 178:641-642

Kisimoto R (1965) Studies on the polymorphism and its role playing in the population growth of the brown planthopper, Nilaparvata lugens Stål. Bull Shikoku Agric Exp Stn Jpn 13:1-106 (in Japanese with English summary)

Kobayashi M, Ishikawa H (1993) Breakdown of indirect flight muscles of alate aphids (Acyrthosiphon pisum) in relation to their flight, feeding and reproductive behavior. J Insect Physiol 39:549-554

Laemmli UK (1970) Cleavage of structure proteins during the assembly of the head of bacteriophage T4. Nature 277:680-685

Lee JM, Hatakeyama M, Oishi K (2000) A simple and rapid method for cloning insect vitellogenin cDNAs. Insect Biochem Mol Biol 30:189-194

Morooka S (1992) Genetic regulation and physiological characteristics of wing form, wing size and body color expression in the brown planthopper, Nilaparvata lugens. Ph. D dissertation of the United Graduate School of Agricultural Sciences, Kagoshima University
Morooka S, Tojo S (1992) Maintenance and selection of strains exhibiting specific wing form and body colour under high density conditions in the brown planthopper, Nilaparvata lugens (Homoptera: Delphacidae). Appl Entomol Zool 27:445-454

Morooka S, Ishibashi N, Tojo S (1988) Relationship between wingform response to nymphal density and black colouration of adult body in the brown planthopper, Nilaparvata lugens (Homoptera: Delphacidae). Appl Entomol Zool 23:449-458

Morooka S, Tanaka Y, Tojo S (2011) Genetic variation in developmental times among four pure lines exhibiting specific wing form and body color in the brown planthopper, Nilaparvata lugens (Hemiptera: Auchenorrhyncha). Appl Entomol Zool 46:229-237

Raikhel AS, Dhadialla TS (1992) Accumulation of yolk proteins in insect oocytes. Annu Rev Entomol 37:217-251

Roff DA (1986) The evolution of wing dimorphism in insect. Evolution 40:1009-1020

Roff DA (1990) The evolution of flightlessness in insects. Ecol Monogr 60:389-421

Shapiro JP, Wasserman HA, Greany PD, Nation JL (2000) Vitellin and vitellogenin in the soldier bug, Podisus maculiventris: identification with monoclonal antibodies and reproductive response to diet. Arch Insect Biochem Physiol 44:130-135

Solbreck C, Anderson DB, Förare J (1990) Migration and the coordination of life cycles as exemplified by Lygaeinae bugs. In: Gilbert F (ed) Insect life-cycles: genetics, evolution and co-ordination. Springer, London, pp 197-214

Tobe SS, Chapman CS (1979) The effects of starvation and subsequent feeding on juvenile hormone synthesis and oöcyte growth in Schistocerca americana gregaria. J Insect Physiol 25:701-708

Towbin H, Staehelin T, Gorden J (1979) Electrophoretic transfer of proteins from polyacrylamide gels to nitrocellulose sheet: procedure and some applications. Proc Natl Acad Sci USA 76:4350-4354

Tufail M, Naeemullah M, Elmogy M, Sharma PN, Takeda M, Nakamura C (2010) Molecular cloning, transcriptional regulation, and differential expression profiling of vitellogenin in two wing-morphs of the brown planthopper, Nilaparvata lugens Stål (Hemiptera: Delphacidae). Insect Mol Biol 19:787-798

Watanabe N (1967) The density effect on the appearance of two wing-forms in the brown planthopper, Nilaparvata lugens and smaller brown planthopper, Laodelphax striatellus. Jpn J Appl Entomol Zool 11:57-61 (in Japanese with English summery)

Weaver RJ, Pratt GE (1981) Effects of starvation and feeding upon corpus allatum activity and oöcyte growth in adult female Periplaneta americana. J Insect Physiol 27:75-83

Weber K, Pringle JR, Obsorn M (1972) Measurement of molecular weights by electrophoresis on SDS-acrylamide gel. Methods Enzymol 26:3-27

Wyatt GR, Davey KG (1996) Cellular and molecular actions of juvenile hormone. II. Roles of juvenile hormone in adult insects. Adv Insect Physiol 26:1-155

Zera AJ, Denno RF (1997) Physiology and ecology of dispersal polymorphism in insect. Ann Rev Entomol 42:207-231 